\title{
Review of the millipede family Paracortinidae Wang \& Zhang 1993 (Diplopoda: Callipodida)
}

\author{
Pavel Stoev ${ }^{1} \&$ Jean-Jacques Geoffroy ${ }^{2}$ \\ ${ }^{1}$ National Museum of Natural History, Tsar Osvoboditel Blvd 1, 1000 Sofia (Bulgaria) \\ E-mail: stoev@nmnh.bas.bg \\ ${ }^{2}$ Muséum National d'Histoire Naturelle, Département Ecologie et Gestion de la \\ Biodiversité, USM 306 Réseaux Trophiques du Sol, 4, avenue du Petit Château F-91800 Brunoy (France) \\ E-mail: geoffroy@mnhn.fr
}

\begin{abstract}
The family Paracortinidae Wang \& Zhang 1993, comprising eleven species from southern China as well as Vietnam, is reviewed. Two new cave-dwelling species, Paracortina chinensis sp. n., from Yunnan Province, China, and P. multisegmentata sp. n., from Thanh Hoa Province, Vietnam, are described. The new discoveries permit a reconsideration of some characters applied in the systematics of the family. The monotypic genus Scotopetalum Shear 2000, with S. warreni Shear 2000, so far known only from two caves near Hanoi, Vietnam, and the apparently polytypic (sub)genera Altum Wang \& Zhang 1993 and Relictus Wang \& Zhang 1993, are synonymised under Paracortina Wang \& Zhang 1993 (s. str.), all syn. n. A distribution map of, and a key to all hitherto described paracortinid millipedes are also provided.
\end{abstract}

Key words - Diplopoda, Callipodida, Paracortinidae, subterranean biology, revision, new species, new synonymy, China, Vietnam.

\section{Introduction}

The millipede family Paracortinidae Wang \& Zhang 1993 (Diplopoda: Callipodida) has hitherto been known to comprise only one genus, Paracortina Wang \& Zhang 1993, with three subgenera and eight species from China (Wang \& Zhang 1993; Stoev 2004). The familial status has been questioned twice (Shear 2000, see also Shear et al. 2003), but no formal synonymy has ever been proposed.

Another paracortinid-like millipede, Scotopetalum warreni Shear 2000, originally erected as a new genus and species of the family Schizopetalidae Verhoeff 1909, has been described from two caves located northwest of Hanoi, Vietnam (Shear 2000; Shear et al. 2003; Enghoff et al. 2004). Recently, Stoev (2004) has expressed serious doubts about the assignment of Scotopetalum. Instead he suggested its close relationship with Paracortina and, providing some additional evidence, he pointed out that the Paracortinidae might prove to represent a family of its own. Until a reliable phylogenetic analysis is accomplished, it seems better to consider all paracortinid millipedes as an independent group of uncertain position within the order Callipodida.

Until now, little has been known about the taxonomy of Paracortinidae (Wang \& Zhang 1993; Wang 1996; Shear 2000; Shear et al. 2003; Stoev 2004). The family is expected to be rich in species, especially when the still poorly explored East Asian faunas become better known. Apart from southern China as well as Vietnam, paracortinids are likely to occur in the extremely poorly prospected adjacent parts of Laos, Myanmar, Thailand and India (cf. Shear et al. 2003, see also Fig. 27).

As a new contribution to the knowledge of the millipede and cave fauna of Vietnam and China (see Wang \& Mauriès 1996; Chen et al. 2001; Deharveng et al. 2001), the present paper provides a brief review of, and a key to, all species currently known in the family. Two new species, Paracortina chinensis sp. n., collected in southern China by the French Expedition "Spéléologie au pays de l'Homme Sauvage" (Degouve 2000; Lips 2000), and P. multisegmentata sp. n., taken in Vietnam by Miss Colani, are described. The new discoveries allow a re-evaluation of some of the characters used in the systematics of the family. Following a critical analysis, the monotypic genus Scotopetalum Shear 2000, and the polytypic (sub)genera Altum Wang \& Zhang 1993 and Relictus Wang \& Zhang 1993, are synonymised under Paracortina Wang \& Zhang, 1993 (s. str.), all syn. n.

\section{Material and methods}

The holotypes and most of the paratypes are housed in the collection of the Muséum National d'Histoire Naturelle, Paris, France (MNHN); further paratypes are deposited in the myriapod collection of the National Museum of Natural History, Sofia (NMNHS). All specimens are preserved in $75 \%$ ethanol. The illustrations were made with a camera 
lucida. The other acronyms accepted concern PT standing for pleurotergite, and $\mathrm{T}$ for telson.

\section{Systematics}

\section{Family Paracortinidae Wang \& Zhang 1993, char. emend.}

Diagnosis. Moderate-sized to large callipodidans with well-developed dorsal crests; ozopores lying at tip of largest crests. Number of pleuroterga varying from 53 to 85 . PT 1-4 each with $5+5$ setae in anterior position; $3+3$ or $4+4$ setae migrating to posterior position on PT 5 ; from PT 6 on, all setae in posterior position. Head convex in both sexes, densely covered with minute setae. Coxae of some of anterior (pre-gonopodial) legs either unmodified or with ventromedial spines. Coxal sacs present on legs $3-23^{1}$. Hypoproct tripartite; paraprocts divided into small dorsal and larger ventral sclerites, each bearing a pair of macrosetae.

Gonopod coxae freely connected through a medial membranous lamina; femoroid with one or two prefemoroidal processes, their apical parts usually covered with macrosetae; basal and central parts of femoroidal stem simple, unbranched; terminal part usually broadened, with several processes; parasolenomere always present.

Adult female with a reduced leg-pair 2 .

The following characters distinguish Paracortinidae from Schizopetalidae, as perceived by Hoffman (1982): cranium convex in both sexes (vs. cranium in males often concavely depressed); coxal sacs present on legs 3-23 (vs. on legs 316); gonopod coxae freely connected through a medial membranous lamina, i.e. calcified sternum is missing (vs. gonopod sternum large and transverse, placed anteriad to the coxae); females with a reduced second leg-pair, composed of two sclerites placed in two rows (vs. either unmodified legs or single sclerite).

\section{Genus Paracortina Wang \& Zhang 1993}

Altum Wang \& Zhang 1993, syn. n.

Relictus Wang \& Zhang 1993, syn. n.

Scotopetalum Shear 2000, syn. n.

Diagnosis. Same as of the family.

Type species. P. leptoclada Wang \& Zhang 1993

\section{Paracortina chinensis sp. $\mathrm{n}$.}

Figs. 1-8

Material examined. Holotype: adult male; $58 \mathrm{PTs}+\mathrm{T}$, length

\footnotetext{
${ }^{1}$ This number has only been found in $P$. chinensis and $P$. wangi. Shear (2000) reported coxal sacs present from 3rd to 19th leg pairs in $S$. warreni, but this could be due to miscounting. Wang \& Zhang (1993) did not mention this character at all.
}

ca. $50 \mathrm{~mm}$, width 2.0-2.2 mm; China, Yunnan, Zheng Xiong County, Ke Ma Dong Cave (Grotte du Brouillard Matinal), 17.08.1999, J. \& B. Lips leg. (No 514, MNHN JB-032). Paratypes: subadult female, same date, locality and collectors (No 514, MNHN JB-032); adult male with undeveloped gonopods, same locality, date and collectors (No 513, MNHN JB-032); subadult male, subadult female, 4 juveniles, same locality, date and collectors (No 515, MNHN JB-032); adult male, 2 subadult females, 7 juveniles, Zheng Xiong County, Liao Jun Dong Cave (Tourist Cave), millipedes collected close to a rat corpse, 17.08.1999, J. \& B. Lips leg. (No 509, MNHN JB-032; one adult male and two subadult females in MNHNS); subadult female, Zheng Xiong County, Da Hei Dong Cave (Grande Grotte Noire), 20.08.1999, J. \& B. Lips leg. (No 551, MNHN JB-032); subadult male, 2 subadult females, one juvenile, same locality, date and collectors (No 540, MNHN JB-032).

Description of localities. The caves Ka Ma Dong, Da Hei Dong and Liao Jun Dong are situated around the town of Zhen Xiong, which is approximately $250 \mathrm{~km}$ south of Chengdu. The largest distance is that between Ka Ma Dong and Liao Jun Dong - ca. $15 \mathrm{~km}$ in a straight line. Da Hei Dong and Lio Jun Dong are situated only $7 \mathrm{~km}$ apart. More information about the results of the French Speleological Expedition in Yunnan, including maps, coordinates, description of the caves, and the history of exploration, can be found in Degouve (2000). Lips (2000) summarised the preliminary information on the fauna of the caves explored. Geoffroy \& Golovatch (2004) described three new polydesmid millipedes from the same caves.

Etymology. To emphasize China as the country of origin.

Description. Length: adult males: 50-60 mm; width $2.0^{-}$ $2.2 \mathrm{~mm}, 55-60 \mathrm{PTs}+\mathrm{T}$; subadults: 48-56 PTs $+\mathrm{T}$; juveniles: 25-39 PTs $+\mathrm{T}$.

Body coloration: All PTs yellow-brownish, posterior margin darker. Dorsal crests of anterior PTs slightly darker; legs yellowish; antennae whitish. Frontal part of head with light brown spots, convex, densely covered with brownish microsetae each emerging from a lighter pit (Fig. 1). Labral area light brown, darker than adjacent parts of head. Ocellaria composed of ca. 30 dark, well-separated ocelli in 5-6 rows. Tömösváry's organs ca 10 times larger than an ocellus (Fig. 1), almost in touch with anterior side of ocellar field. Antennae moderately long, extending beyond posterior edge of PT 6 when folded backward. Antennomere length ratios: $2=3>4=5>6$; article 5 with a tuft of fine setae ( $t s$ ) posteriorly (Fig. 2). Head as broad as PT 5. PTs 6 and 7 in male strongly enlarged.

Table 1. Partial chaetotaxy in P. chinensis sp. n.

\begin{tabular}{ccc}
\hline & Anterior setae & Posterior setae \\
\hline Collum & $5+5$ & - \\
2nd PT & $5+5$ & - \\
3rd PT & $5+5$ & - \\
4th PT & $5+5$ & $\mathrm{~b}, \mathrm{c}, \mathrm{e}+\mathrm{b}, \mathrm{c}, \mathrm{e}$ \\
5th PT & $\mathrm{a}, \mathrm{d}+\mathrm{a}, \mathrm{d}$ & $5+5$ \\
6th PT & - & $5+5$ \\
7th PT & - & $5+5$ \\
8th PT & - & \\
\hline
\end{tabular}



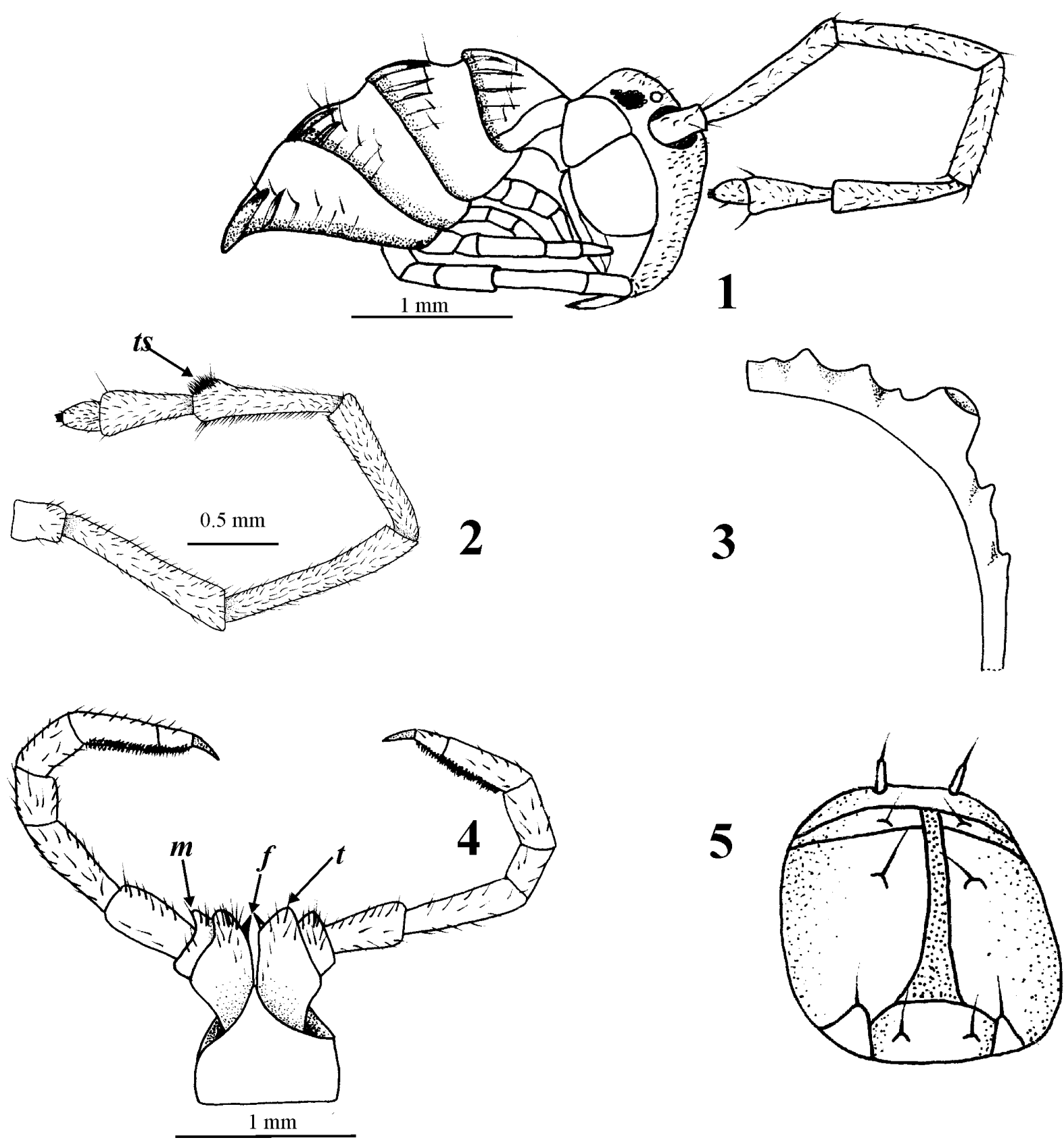

Figs. 1-5. Paracortina chinensis sp. n.: 1-Head and anterior pleurotergites, lateral view; 2-right antenna, lateral view; $3^{-}$-cross ${ }^{-}$section of a middle hemipleurite, anterior view; 4-male 7th leg pair, anterior view; 5-telson, ventrolateral view. Abbreviations, see text.

All crests well-developed; from PT 6 on, third crest strongly pronounced and resembling paranota $(=$ paraterga) in certain Polydesmida. Crest formula: $3>1=2>4$ (Fig. 3). Four crests between poriferous crests on PT 7. Ozopores present from PT 6 to pre-penultimate one, placed on tip of 3rd crest. Setal pattern as in Table 1.

First and 2nd leg-pairs markedly shorter, 3rd slightly shorter than subsequent legs. Tarsi 1-3 single; biarticulated from 4th to ultimate pair. Other legs generally long, ending with a large claw. Coxal sacs present on legpairs 3 to 23 . Coxae 2 with a very small and inconspicuous anterior process and a posterior gonopore, latter placed on a small cone. Male coxa 7 with a short, pointed, mesal $(f)$ and a shorter, more oval, lateral process $(t)$; trochanter prolonged ventrally $(m)$ (Fig. 4). Remaining legs normal. Tarsal pads generally small, well visible from 3rd to about 9-10th leg-pair; gradually reduced in size towards telson to disappear completely since about midbody legs. Hypoproct tripartite; medial sclerite largest, subrectangular, bearing two paramedian macrosetae. Lateral sclerites with a single macroseta each. Anal valves smooth, each divided into a small dorsal and a large ventral sclerite, with a pair of macrosetae. Spinnerets moderately thin and long, each surmounted by a macroseta (Fig. 5). 

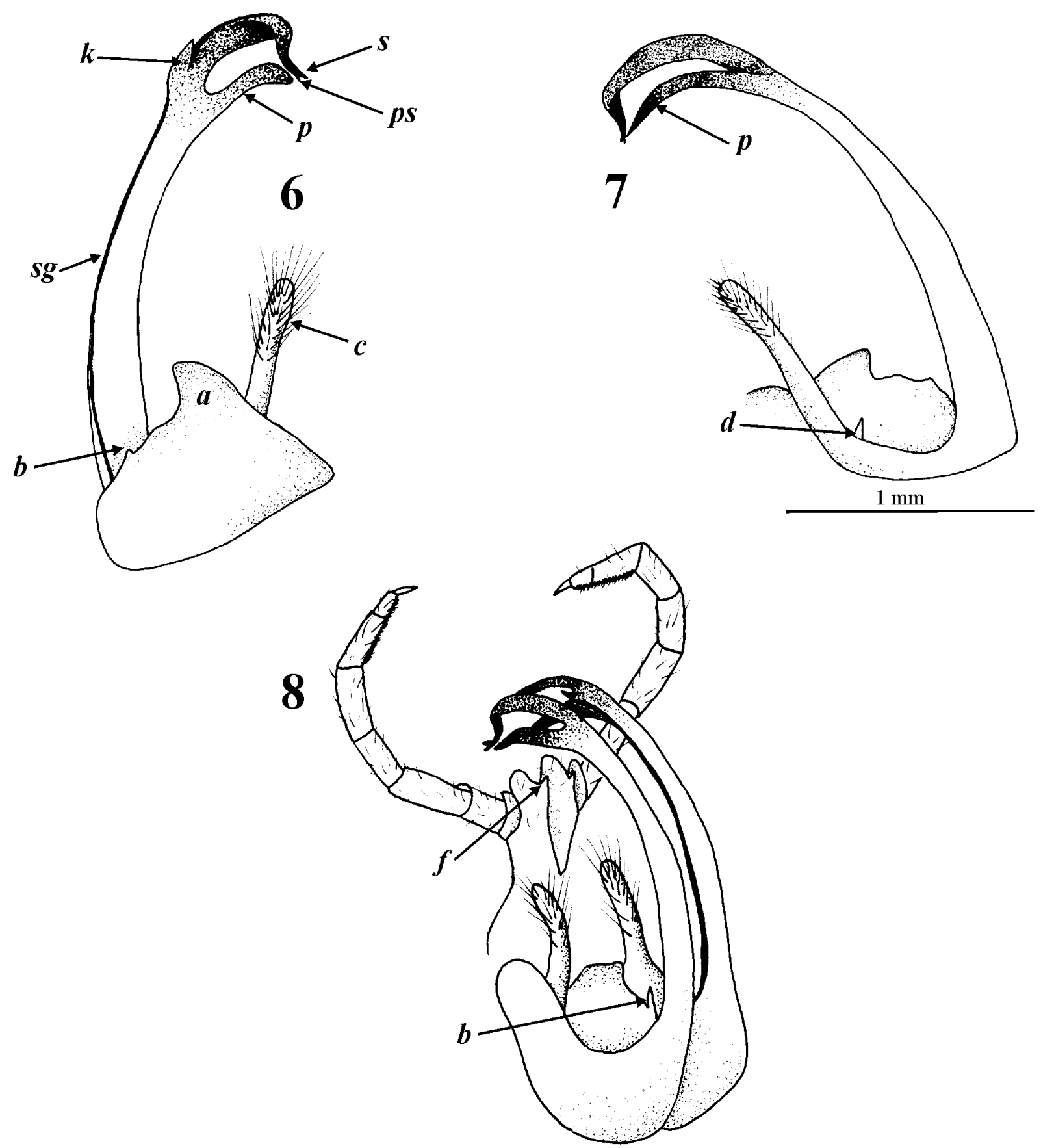

Figs. 6-8. Paracortina chinensis sp. n.: 6-male gonopod, anteromesal view; 7-same, lateral view; 8-male gonopods and 7th leg pair, position in situ, posterolateral view. Abbreviations, see text.

Gonopods as in Figs. 6-8. Coxa strongly broadened mesally, bearing a large, subtriangular, ovoid, anterior process $(a)$ and a smaller tooth $(b)$ emerging close to base of femoroid (Figs. 6 and 8). Anterior process about half the length of prefemoroidal process; $b$ sometimes very short (Figs. 6-7). Femoroid with large prefemoroidal processes (c); its apical part densely covered with long setae. A highly inconspicuous, bare, additional prefemoroidal processes (d) can be observed near base of $c$ (Fig. 7).
Femoroidal stem long, subfalcate, directed cephalad; its terminal part protruding beyond pleurotergal edge, resting on leg-pairs 6 and 7. Stem yellowish basally, black terminally. A long, pointed, subterminal process $(p)$ emerging on lateral side of femoroid; a smaller one $(k)$ present on mesal side. Seminal groove $(s g)$ running mesally, terminating on solenomere $(s)$, latter subequal in length to parasolenomere (ps) (Fig. 6).

Subadult females approximately as long as males, PTs 6 

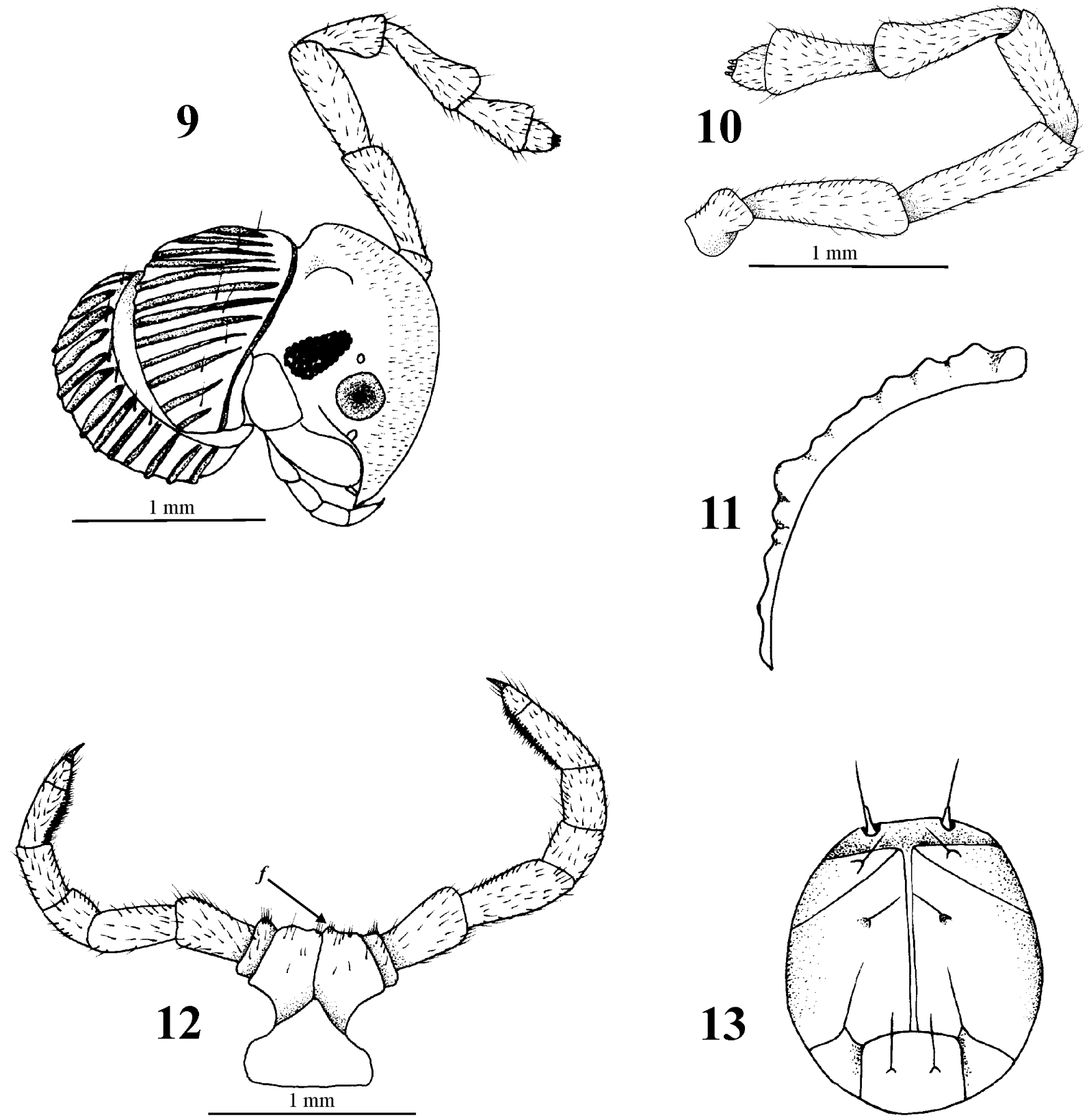

Figs. 9-13. Paracortina multisegmentata sp. n.: 9-Head and anterior pleurotergites, dorsolateral view; 10-right antenna, lateral view; 11cross $^{-}$section of a middle hemipleurite, anterior view; $12-$ male 7 th leg pair, anterior view; 13 -telson, ventral view. Abbreviations, see text.

and 7 not enlarged. Leg-pair 2 normal. All legs with unmodified trochantera and coxae. Cyphopods small, partly extruded, their terminal parts divided.

\section{Paracortina multisegmentata sp. $\mathrm{n}$.}

Figs. 9-17

Material examined. Holotype: adult male; $85 \mathrm{PTs}+\mathrm{T}$, length 60-70 mm, width $2.95 \mathrm{~mm}$; Vietnam, Thanh Hoa Province, Ngoc-Lac, Moc-Trach Cave, alt. 15 m, 8-10.12.1929, Colani leg. (MNHN JB-033). - Paratypes: three adult males, fragments of at least two adult specimens, same date, locality and collector (MNHN JB-033; one male in MNHNS); one specimen without head and anterior PTs, Thanh Hoa Province, Loc Thinh, Loc Thinh Cave, alt. 50 m, 14.12.1929, Colani leg. (MNHN JB033).

Description of localities. The two localities are situated in Thanh Hoa Province, approximately $150 \mathrm{~km}$ south of Hanoi. We could not find more geographical information about the Moc-Trach and Loc Thinh caves, which obviously are not far away from each other. Keeping in mind that only a small part of the Vietnamese caves have been investigated and mapped (Deharveng et al. 2001), more evidence 
concerning their exact location, geomorphology and fauna are likely to become available in the future.

Etymology. To emphasize the large number of pleurotergites (segments).

Description. Length: body heavily coiled and difficult to measure, but approximately $60^{-}-70 \mathrm{~mm}$; width $2.9^{-}-3.1 \mathrm{~mm}$, 81-85 PTs + T.

Body coloration (after 75 years of preservation) uniformly light brownish; legs white-yellowish. Head convex, approximately as broad as PT 5; its frontal side densely covered with fine setae. Labral area light brown. Ocellaria composed of ca. 40 dark ocelli in 5-6 rows. Tömösváry's organs slightly larger than an ocellus, placed between the eyes and antennal base (Fig. 9). Antennae moderately long but shorter than those of $P$. chinensis, extending beyond posterior edge of PT 5 when folded backward.
Table 2. Partial chaetotaxy in P. multisegmentata sp. n.

\begin{tabular}{ccc}
\hline & Anterior setae & Posterior setae \\
\hline Collum & $5+5$ & - \\
2nd PT & $5+5$ & - \\
3rd PT & $5+5$ & - \\
4th PT & $5+5$ & $\mathrm{~b}, \mathrm{c}, \mathrm{d}, \mathrm{f}+\mathrm{b}, \mathrm{c}, \mathrm{d}, \mathrm{f}$ \\
5th PT & $\mathrm{a}, \mathrm{e}+\mathrm{a}, \mathrm{e}$ & $7+7$ \\
6th PT & - & $7+7$ \\
7th PT & - & $7+7$ \\
8th PT & - & \\
\hline
\end{tabular}

Antennomere length ratios: $3>2>4=5>6$ (Fig. 10). Male PTs 6 and 7 strongly enlarged.

Apart from collum, metazona of remaining PTs strongly expanded. All crests, starting from collum, well-developed; from PT 6 on, 8th (poriferous) crest strongly pronounced, resembling paranota in certain Polydesmida (Fig. 11). Crest
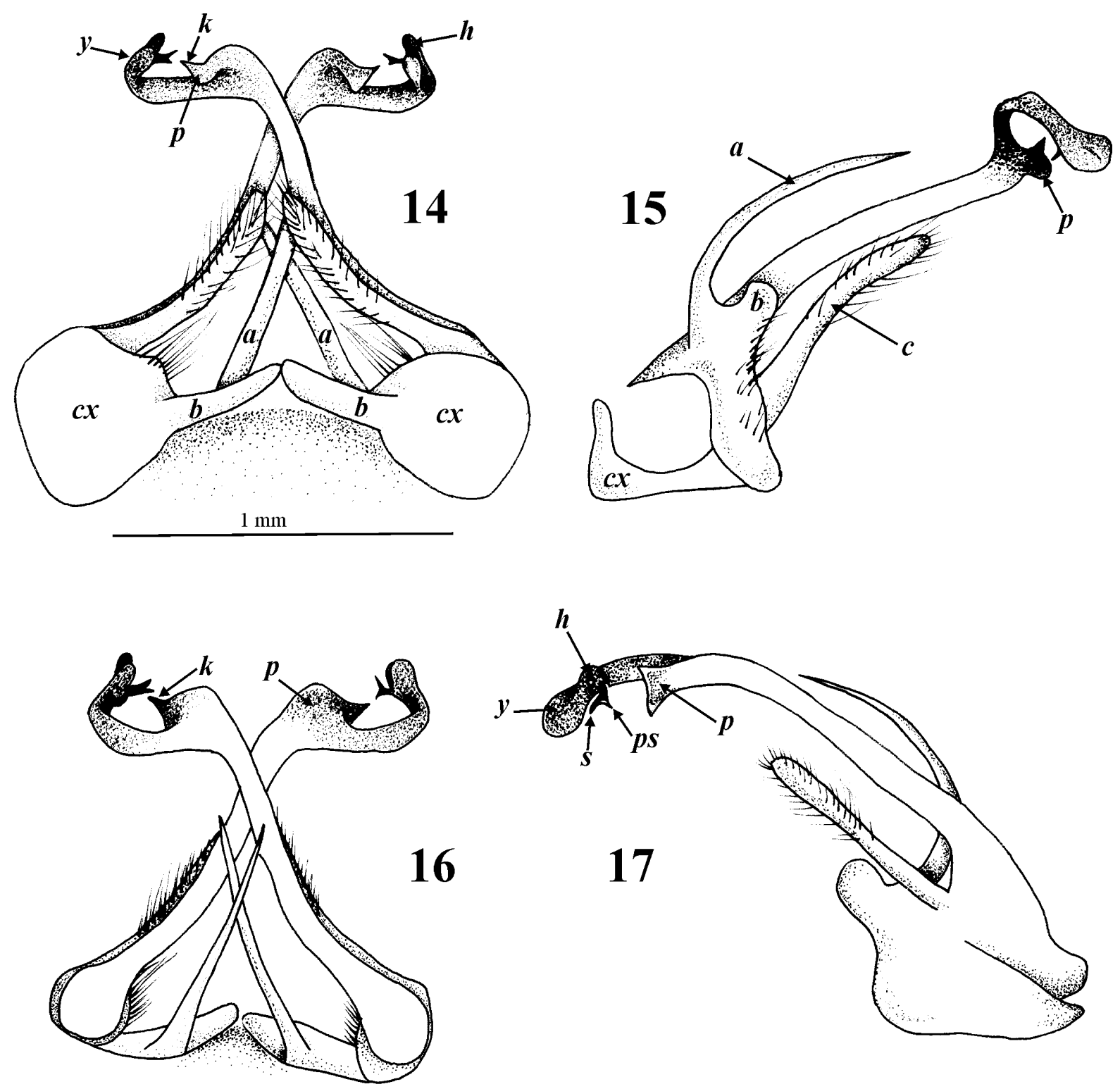

Figs. 14-17. Paracortina multisegmentata sp. n., male gonopods: 14-anterior view; 15-anteromesal view; 16-posterior view; 17-lateral view. Abbreviations, see text. 

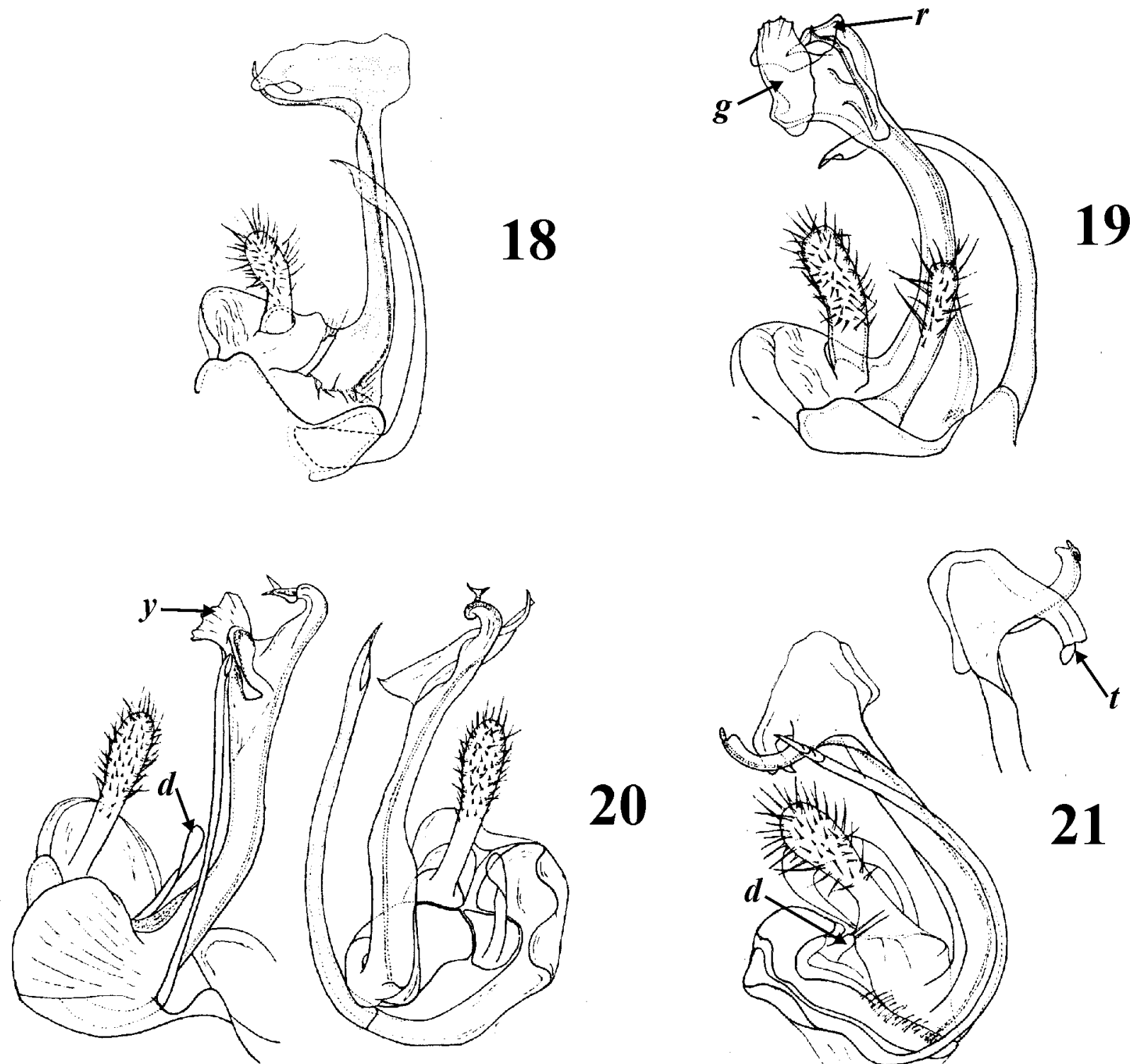

20
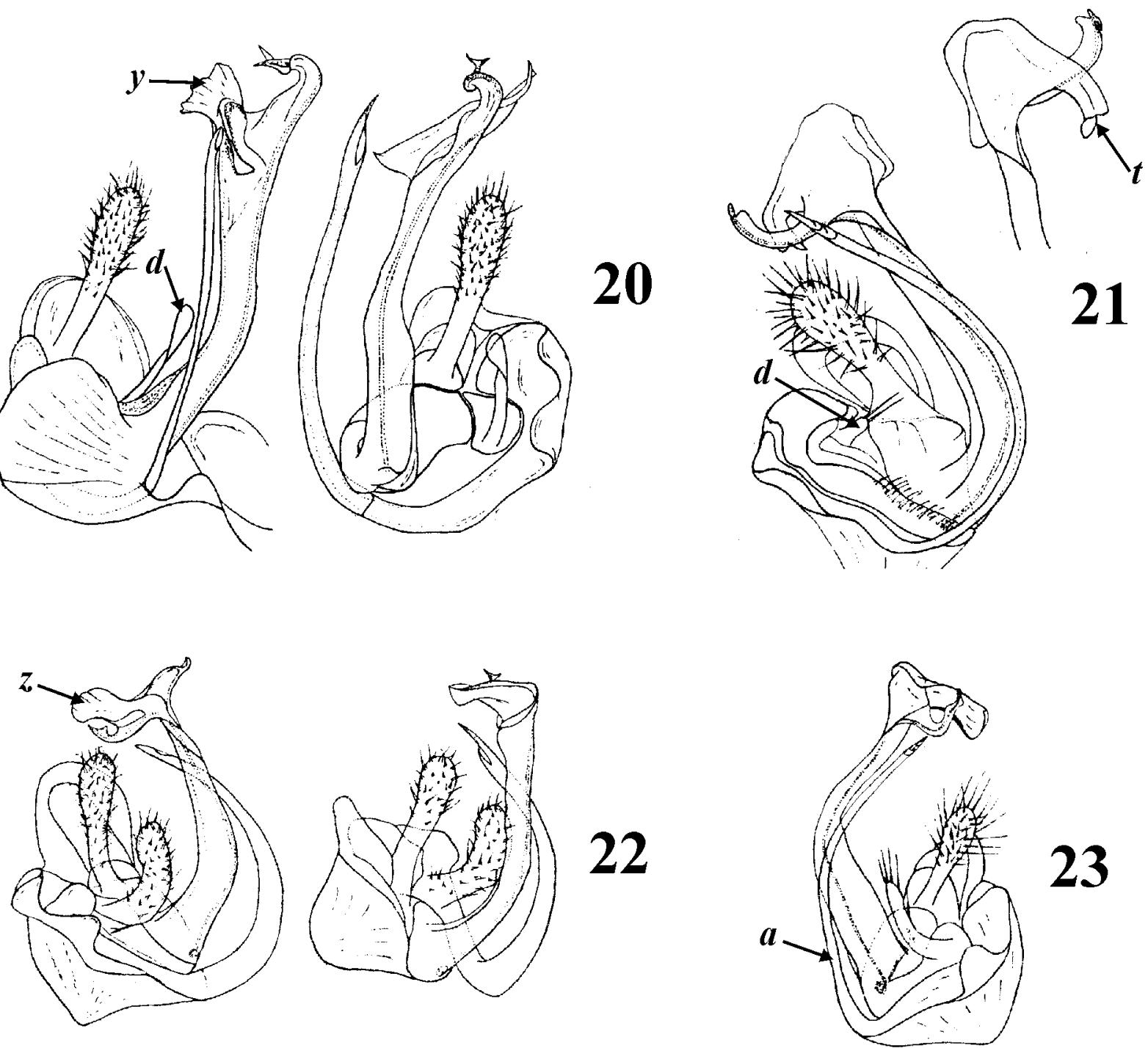

Figs. 18-23. Paracortina spp., male gonopods, after Wang \& Zhang (1993): 18-P. carinata; 19-P. leptoclada; 20-P. serrata; 21-P. stimula; 22-P. thallina; 23-P. viriosa. Abbreviations, see text. 
formula: $8>10=12>2=4=6>1=3=5=7=9$. Fourteen crests between the poriferous crests on PT 7. Ozopores present from PT 6 to pre-penultimate one, placed at tip of 8th crest. Setal pattern as in Table 2.

Leg-pairs 1 and 2 markedly shorter, 3rd slightly shorter than subsequent legs. Tarsi 1-3 single; bi-articulated from 4th to ultimate pair. Coxal sacs present from 3rd at least to leg-pair 18, perhaps even further (presumably until 23rd). Coxae 2 with a gonopore posteriorly, laying on a small cone. Coxae 7 subquadrate, with small mesal spines $(f)$; prefemora slightly incrassate (Fig. 12). Tarsal pads generally small, present from 3rd to about leg-pair 10 or 11 . Hypoproct tripartite, medial sclerite largest, rectangular, bearing two paramedian macrosetae. Lateral sclerites with a single long seta each. Anal valves smooth, divided into a small dorsal and a large ventral sclerite, each with a pair of long setae. Spinnerets thin and long, each surmounted by a macroseta (Fig. 13)

Gonopods as in Figs 14-17. Coxae expanded mesally, connected through a medial lamina. Two coxal processes ( $a$ and $b$ ) emerging lateral to femoroid; $a$ longer, about half as long as femoroid, slender, curved, pointed apically; $b$ short, equally broad, with an ovoid apex (Figs. 14 and 16). Terminal parts of processes $b$ in touch with each other, both hidden inside PT; processes $a$ crossing each other, extending beyond PT edge. Femoroid with long, slightly curved prefemoroidal processes $(c)$ densely covered with long setae (Fig. 15). Femoroidal stem long, slender, subfalcate, extending far beyond PT edge, its terminal part reaching leg pair 4 or 5 , directed anterolaterally. Basal part of femoroid yellowish, terminal one brownish. Subterminal part of femoroidal stem broadened, forming an ovoid process $(p)$ bearing a distal spine $(k)$ (Figs. 14 and 16). Femoroid ending with two ovoid processes, a larger anterior $(y)$ and a
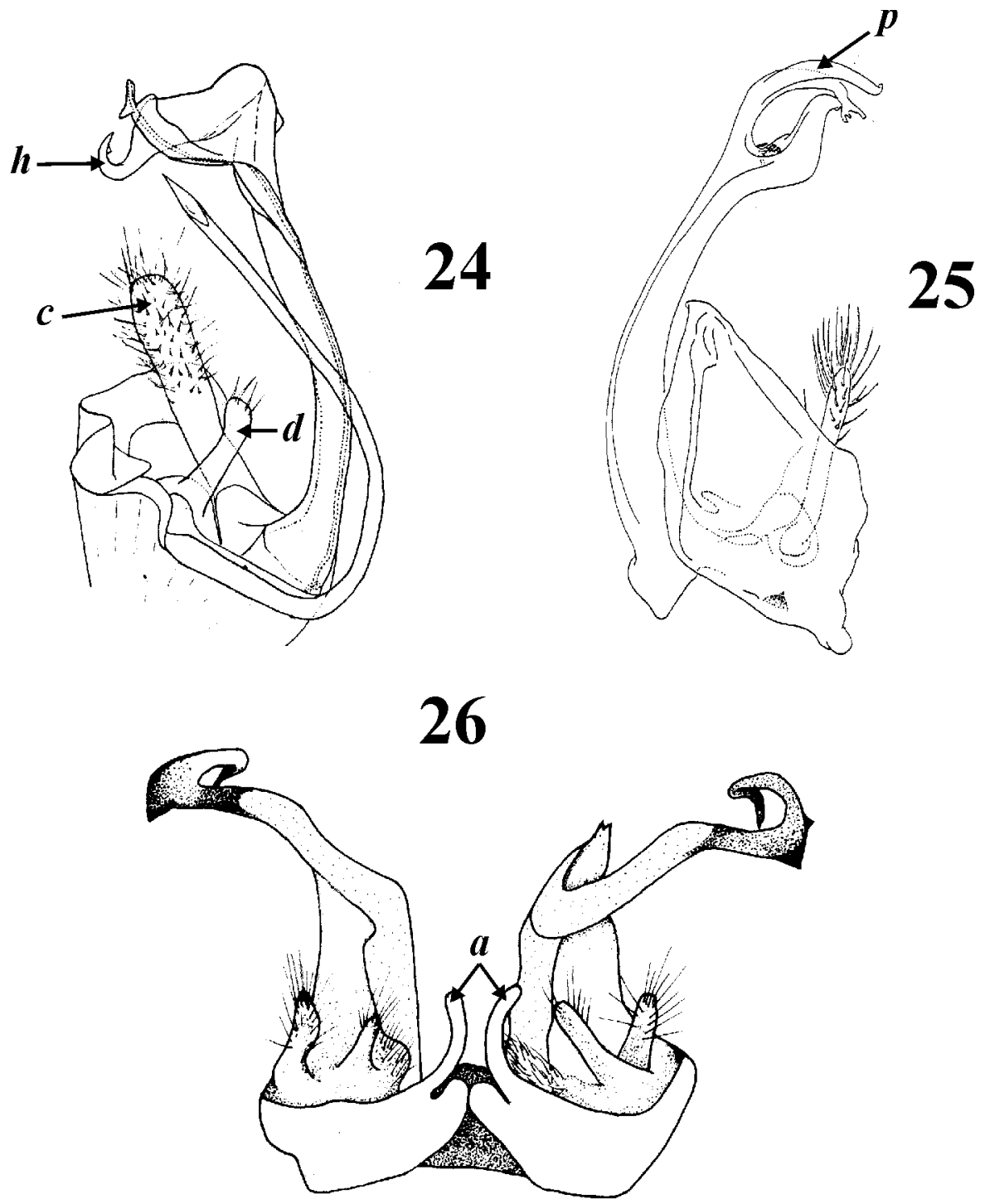

Figs. 24-26. Paracortina spp., male gonopods, after Wang \& Zhang (1993), Shear (2000, reprinted courtesy of Myriapodologica) and Stoev (2004, reprinted courtesy of Zootaxa): 24-P. voluta; 25-P. warreni; 26- . wangi. Abbreviations, see text. 
smaller posterior $(h)$, the latter terminated by a solenomere $(s)$ and a parasolenomere (ps) (Fig. 17).

Female unknown.

\section{Discussion}

Both new species differ significantly from the other congeners by their peculiar external and gonopod structures. The large number of pleurotergites in $P$. multisegmentata, the pronounced dorsal crests and the presence of $7+7$ pleurotergal setae from PT 6 on, coupled with the singular gonopod shape are highly characteristic. P. chinensis is distinguished from the other species from Yunnan mainly based on gonopod conformation, i.e. presence of both a large subtriangular $(a)$ and a smaller coxal process $(b)$, of a larger $(c)$ and a smaller, rudimentary prefemoroidal process $(d)$, and of a comparatively simple femoroid bearing two subterminal processes ( $k$ and $p$ ).

Such a set of characters brings $P$. chinensis very close to
Scotopetalum warreni, the latter originally described as a new genus and species from Vietnam. The genus Scotopetalum was characterised as follows: “...lacking any indication of a sternum or coxal process in the gonopod, and in having no crest transition (full number of primary crests present on all segments). Each hemipleurotergite bears a series of five setae; all are in the anterior position on segments $1-4$, setae $b, d$, e migrate posteriorly on segment 5 , and all setae are posterior on segment 6". As nearly all of these features are also dispersed among species of Paracortina, the erection of a new genus could have hardly been justified, as is the case for the assignment of Scotopetalum within Schizopetalidae. Indeed, superficially the subtriangular gonocoxae versus those with long subfalcate processes as well as the existence of only one large prefemoroidal process in $S$. warreni seem striking enough to be taken as characters of generic rank. However, this does not prove to be the case, because clearly intermediate states

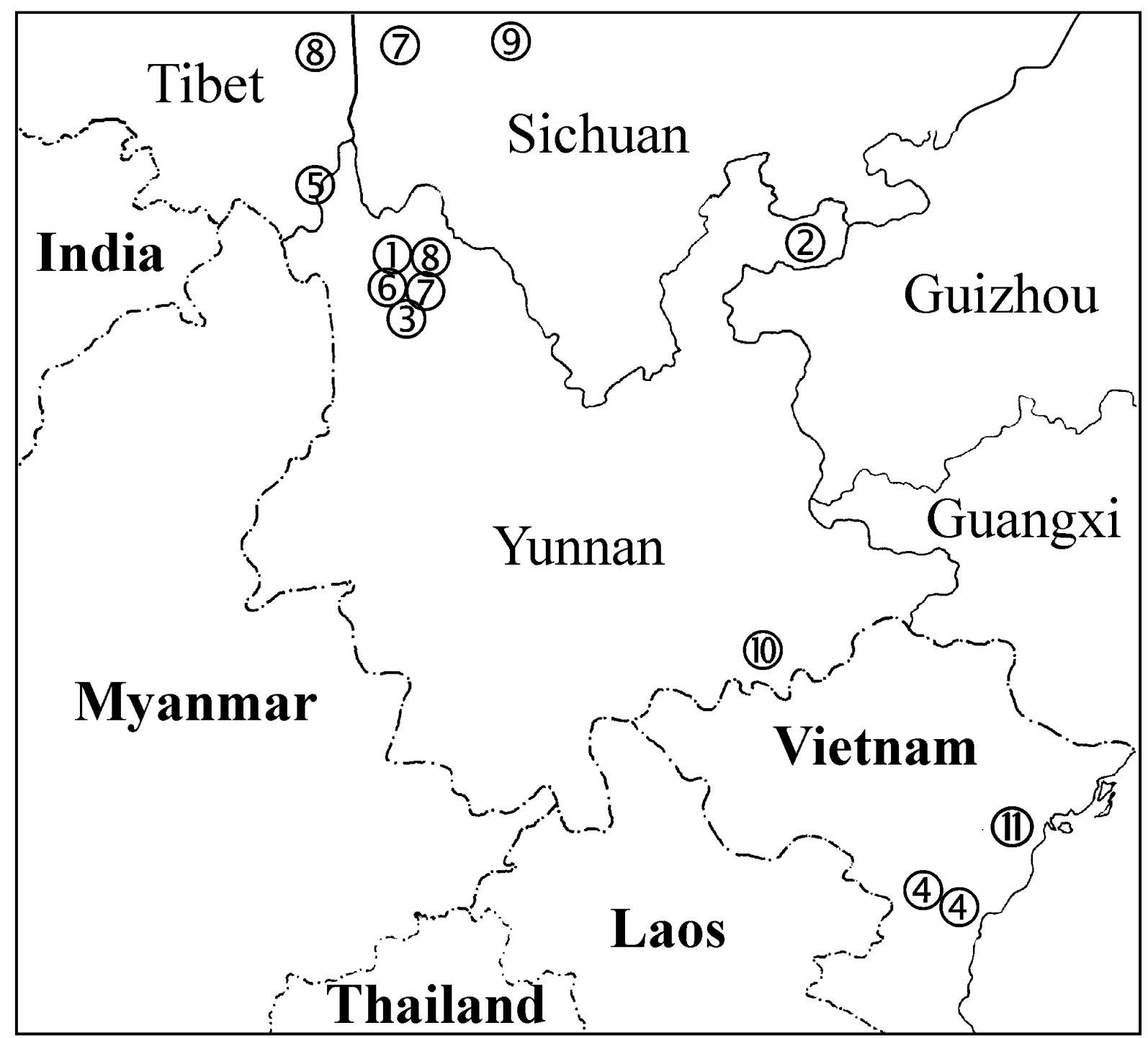

Fig. 27. General distribution of the family Paracortinidae: $1-P$. carinata; $2-P$. chinensis; $3-P$. leptoclada; 4-P. multisegmentata; 5-P. serrata; 6-P. stimula; 7-P. thallina; 8-P. viriosa; 9-P. voluta; 10-P. wangi; 11-P. warreni. 
like the short subfalcate gonocoxal process and the very small, reduced prefemoroidal process are observed in Paracortina wangi and P. stimula (Figs. 21 and 26). As a result, the diversity in shape of the gonopods in Paracortinidae appears to be much greater than had previously been recognised, increasing with the description of each new species. Since maintaining the genus Scotopetalum is no longer justified, we propose here the following new synonymy and combination: Paracortina Wang \& Zhang $1993=$ Scotopetalum Shear 2000, syn. n., and Paracortina warreni (Shear 2000), comb. n.

In addition to gonopod structure, $P$. chinensis is distinguished from $P$. warreni by several peripheral characters like the larger body $(50-60$ versus $32 \mathrm{~mm})$ and the greater number of PTs (55-60 versus $\left.53^{2}\right)$, with only four dorsal crests between poriferous crests (versus 12 crests), about 30 ocelli in 5-6 rows (versus 15 ocelli in 3 rows).

As first suggested by Shear (2000) and recently discussed by Stoev (2004), the (sub)genera Altum and Relictus may prove to be polyphyletic, being established solely on the basis of the number and arrangement of pleurotergal setae. To support this assumption, the cladistic analysis conducted by Wang (1996) shows Relictus stimulus as the "sister group of all other extant paracortinids", which contradicts his earlier systematic arrangement. In addition, the setal pattern in Callipodida has recently been found to be unstable at the generic level, varying considerably among species or even specimens in such European genera as Balkanopetalum Verhoeff, 1926 (Stoev \& Enghoff 2003) or Apfelbeckia Verhoeff, 1896 (Enghoff, Stoev \& Hoffman, in prep.). At the same time, setal patterns show constancy in all Nearctic and some Palearctic genera, e.g. Callipus Risso, 1826 (cf. Shear 2000; Stoev \& Enghoff 2003). Paracortina is another genus, in which the species are more or less uniform in gonopod conformation, yet with different setal arrangements from PT 5 onwards. As a result, we do not hesitate to propose the following new synonymy: Paracortina Wang \& Zhang 1993=Altum Wang \& Zhang $1993=$ Relictus Wang \& Zhang 1993, both syn. n. Among these names, Paracortina, having been proposed first, is the one to be accepted as valid.

It is noteworthy that, among Paracortinidae, at least three troglomorphic species have been found, e.g. $P$. wangi, $P$. warreni and $P$. chinensis, all showing different degrees of eye reduction. One more species, Sinocallipus simplipodicus Zhang 1993 (Callipodida: Sinocallipodidea: Sinocallipodidae), also known from caves in southern China, has only 16 ocelli (Zhang 1993³). Though callipodidans are quite common in caves of southern Europe, none of the known species shows such a strong degree of eye reduction as do their East Asian counterparts.

\footnotetext{
${ }^{2}$ It is not clear whether the telson was included in the count. Shear et al. (2003) reported S. simplipodicus epigeically in southern Laos, but eventually this record must be referred to another, yet undescribed species of Sinocallipus (Stoev, Geoffroy \& Mauries, in prep.).
}

Stoev (2004) has even speculated that 2-3 rows of ocelli (versus triangular ocellaria) could probably be treated as another character of the entire family Paracortinidae. Now, however, with the new evidence at hand, this suggestion appears to be redundant.

A key to species of Paracortinidae will conclude this paper. It is only to be taken as temporary, because one may expect many more representatives of this millipede family to be revealed in the adjacent parts of East and Southeast Asia (Fig. 27).

\section{Key to species of the family Paracortinidae}

1. Gonocoxa subtriangular $\cdots \ldots \ldots \ldots \ldots \ldots \ldots, 2$ Gonocoxa always with a long subfalcate process $(a$ in Figs. 14-15, 23, 26) $\cdots \cdots \cdots \ldots \ldots \ldots \ldots \ldots \ldots$

2. Body size: $32 \mathrm{~mm}$; 15 ocelli in 3 rows; $6+6$ dorsal crests between poriferous crests; terminal part of gonofemur with a long process $(p)$; gonocoxa reaching about midway of gonofemur (Fig. 25) $\ldots \ldots \ldots \ldots \ldots \ldots \ldots \ldots$ …P. warreni (Shear) (caves NW of Hanoi, Vietnam) Body size: $50-60 \mathrm{~mm}$; 30 ocelli in 5-6 rows; $2+2$ dorsal crests between poriferous crests; femoroidal process $(k)$ small; gonocoxa shorter (Fig. 6) $\cdots \cdots \ldots \ldots \ldots \ldots$ … P. chinensis sp. n. (caves in Zheng Xiong County, NE Yunnan, China)

3. 81-85 PTs; a single prefemoroidal process ( $c$ in Fig. 15) …P. multisegmentata sp. n. (caves in Thanh Hoa Province, Vietnam)

50-60 PTs; gonofemur with two prefemoroidal processes ............................ 4

4. Larger gonocoxal process (a) ovoid apically, about $1 / 4$ times as long as femoroid; terminal part of femoroidal stem heavily twisted; cave species (Fig. 26) $\cdots . . . .$. ........ P. wangi Stoev (caves in Mengzi County, southern Yunnan, China) Larger gonocoxal processes pointed apically, about $3 / 4$ to $4 / 5$ times as long as femoroid; terminal part of femoroidal stem less strongly twisted; epigeic species $\cdots \cdots \cdots \cdot 5$ 5. Prefemoroidal process $(d)$ without setae, its terminal part slightly curved; medial branch of femoroid $(y)$ serrate (Fig. 20); male coxa 7 with two processes........ .................. serrata (Wang \& Zhang)

(De Qin County, Tibet, China) Prefemoroidal processes not curved apically, bearing at least two setae; femoroid without serrate parts; male coxa 7 without processes $\ldots \ldots \ldots \ldots \ldots \ldots \ldots \ldots, 6$

6. $7+7$ posterior setae on PT $6 \ldots \ldots \ldots \ldots \ldots \ldots \ldots$ $5+5$ to $6+6$ posterior setae on PT $6 \quad \cdots \cdots \cdots \cdots$

7. Gonopods generally small; prefemoroidal processes $(d)$ reduced, bearing two apical setae; terminal part of femoroid with a distal process $(t)$ directed down, i.e. in opposite direction to solenomere; coxal process higher than solenomere base (Fig. 21) $\cdots$ P. stimula (Wang \&

Zhang) (Zhong Dian County, NW Yunnan, China) Gonopods larger; both prefemoroidal processes well-developed and densely covered with macrosetae; terminal 
part of femoroid with a lobe ${ }^{-}$shaped process $(z)$; coxal process shorter than solenomere base (Fig. 22) …... ................ thallina (Wang \& Zhang)

(Ba Tang County, Sichuan and Zhong Dian County, NW Yunnan, China)

8. $6+6$ posterior setae on PT $6 \ldots \ldots \ldots \ldots \ldots$ $5+5$ posterior setae on PT $6 \quad \ldots \ldots \ldots \ldots \ldots \ldots$

9. First male leg-pair with two coxal processes; gonocoxal process falcate, directed down; both prefemoroidal processes well-developed and covered with numerous macrosetae; terminal part of femoroid with two lobeshaped processes ( $g$ and $r$ ) surrounding a solenomere (Fig. 19) …....... leptoclada Wang \& Zhang

(Zhong Dian County, NW Yunnan, China) First leg-pair normal; gonocoxal process slenderer and more straight, directed upwards; prefemoroidal processes of different size and shape ( $c$ and $d$ ); smaller one bearing 8-9 apical setae; terminal part of femoroid with a hooklike process $(h)$ (Fig. 24) $\cdots P$. voluta Wang \& Zhang (Ya Zhang County, Sichuan, China)

10. Coxal process $(a)$ thin, reaching solenomere base; terminal part of femoroid tripartite (Fig. 23) …...... ... P. viriosa (Wang \& Zhang) (Zhong Dian County,

NW Yunnan and Mang Kang County, Tibet, China) Coxal process shorter and stouter; terminal part of femoroid bipartite (Fig. 18) $\ldots \ldots \ldots \ldots \ldots \ldots \ldots$

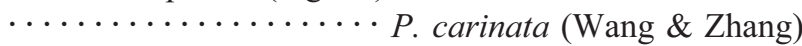

(Zhong Dian County, NW Yunnan, China)

\section{Acknowledgments}

We are most grateful to Prof. Sergei Golovatch (Moscow) for his valuable comments on the final draft. Dr. Gregory Edgecombe (Sydney) kindly improved the English of the manuscript. Special thanks are due to Josiane and Bernard Lips who entrusted their valuable material for study and preservation in the MNHN and NMNHS collections. Mrs. Fani Bozarova, NMNHS, inked the illustrations. Prof. William Shear (Hampden-Sydney, USA) is thanked for permission to reprint the drawing of Scotopetalum warreni originally published in Myriapodologica. Permission for reprinting the illustration of Paracortina wangi has been received from Zootaxa. Part of the work was undertaken with the support rendered to the first author by the European Commission's programme "Transnational Access to Major Research Infrastructures" through the project COLPARSYST for a two- week long stay at the MNHN, Paris in March-April 2004.

\section{References}

Chen, Z., Decu, V., Juberthie, C. \& Uéno, S.I., 2001. China. In: Juberthie, C. \& Decu, V. (Eds) Encyclopaedia Biospeologica, Tome III, Société Internationale de Biospéologie, Moulis, Bucarest, 17631781.

Degouve, P., 2000. Reconnaissance dans la province du Yunnan. In: Degouve, P., Lips, B. \& Lips, J. (Eds) Spéléologie au Pays de l'H omme Sauvage, No 4-1999, 4ème expédition spéléologique en Chine. Sichuan, Yunnan, ALK-FFS, Lyon, 85-104.

Deharveng, L., Le Cong Kiet \& Bedos, A., 2001. Vietnam. In: Juberthie, C. \& Decu, V. (Eds) Encyclopaedia Biospeologica, Tome III, Société Internationale de Biospéologie, Moulis, Bucarest, 20272037.

Enghoff, H., Golovatch, S. \& Nguen Duc Anh, 2004. A review of the millipede fauna of Vietnam (Diplopoda). Arthropoda Selecta, 13 (1-2): 29-43.

Geoffroy, J.J. \& Golovatch, S.I., 2004. Some polydesmidan millipedes from caves in southern China (Diplopoda: Polydesmida), with descriptions of four new species. Arthropoda Selecta, 13 (1): 19-28.

Hoffman, R., 1982. Diplopoda. In: S. Parker (ed.) Synopsis and Classification of Living Organisms, 2: 689-724.

Lips, J., 2000. Biologie. In: Degouve, P., Lips, B. \& Lips, J. (Eds) Spéléologie au Pays de l'Homme Sauvage, No 4-1999, 4ème expédition spéléologique en Chine. Sichuan, Yunnan, ALK-FFS, Lyon, 105-115.

Shear, R., 2000. A new genus and species of callipodidan milliped from Vietnam (Callipodida, Schizopetalidae). Myriapodologica, 6 (11): 95-100

Shear, W., Shelley, R. \& Heatwole, H., 2003. Occurrence of the milliped Sinocallipus simplipodicus Zhang, 1993 in Laos, with reviews of the Southeast Asian and global callipodidan faunas, and remarks on the phylogenetic position of the order (Callipodida: Sinocallipodidea: Sinocallipodidae). Zootaxa, 365: 1-20.

Stoev, P., 2004. The first troglomorphic species of the millipede genus Paracortina Wang \& Zhang, 1993 from south Yunnan, China (Diplopoda: Callipodida: Paracortinidae). Zootaxa, 441: 1-8.

Stoev, P. \& Enghoff, H., 2003. Systematics, phylogeny and biogeography of genus Balkanopetalum Verhoeff, 1926 (Diplopoda: Callipodida: Schizopetalidae). Zootaxa, 272: 1-26.

Wang, D., 1996. A preliminary study on phylogeny and biogeography of the family Paracortinidae (Myriapoda: Callipodida): a cladistic analysis. In: Acta Myriapodologica, Geoffroy J.J., Mauriès J.P. \& Nguyen Duy-Jacquesmin M., Eds. Mémoires du Muséum national d'Histoire Naturelle, 169: 307-311.

Wang, D. \& Mauriès, J.P., 1996. Review and perspective of study on Myriapodology of China. In: Acta Myriapodologica, Geoffroy J.J., Mauriès J.P. \& Nguyen Duy-Jacquesmin M., Eds. Mémoires du Muséum national d'Histoire Naturelle, 169: 81-99.

Wang, D. \& Zhang, C., 1993. A new family of millipeds (Diplopoda: Callipodida) from Southwestern China. Peking National History Museum Mémoires, 53: 375-390.

Zhang, C., 1993. Diplopoda from Yunnan caves. II. Contribution to the study of a new cavernous taxon of the nematophoran millipeds (Diplopoda: Coelocheta: Callipodida). Proceedings of the XI International Congress of Speleology, Beijing, China, 1993, 128130.

Received June 11, 2004 / Accepted October 18, 2004 